\title{
Angioleiomyoma in the Orbital Apex: A Case Report
}

\author{
Boeun Lee ${ }^{1}$, Soo Jeong Park ${ }^{1,2}$, Ju Hyung Moon ${ }^{1,2,3}$, Se Hoon Kim²,4, Jong Hee Chang ${ }^{1,2,3}$, Sun Ho Kim ${ }^{1,2,3}$, Eui Hyun Kim²,23 \\ Departments of ${ }^{1}$ Neurosurgery, ${ }^{4}$ Pathology, Yonsei University College of Medicine, Seoul, Korea \\ ${ }^{2}$ Brain Tumor Center, Severance Hospital, Seoul, Korea \\ ${ }^{3}$ Brain Research Institute, Yonsei University College of Medicine, Seoul, Korea
}

Received December 24, 2018

Revised May 1, 2019

Accepted June 11, 2019

\section{Correspondence}

Eui Hyun Kim

Department of Neurosurgery,

Yonsei University College of Medicine,

50-1 Yonsei-ro, Seodaemun-gu,

Seoul 03722, Korea

Tel: $+82-2-2228-2165$

Fax: $+82-2-393-9979$

E-mail: euihyunkim@yuhs.ac

\begin{abstract}
A 56-year woman presented eyeball pain and blurred vision. MRI revealed a small well-delineated solid tumor in the apex of right orbit with optic nerve compression. Intraoperatively, the tumor was found very fibrous, hypervascular and adhesive to surrounding structures. The tumor was completely removed with the combination of endoscopic and microscopic technique. Patient experienced transient oculomotor nerve palsy, which completely recovered 3 months after surgery. Herein we report a rare case of angioleiomyoma in the orbital apex.
\end{abstract}

Key Words Angioleiomyoma; Endoscopic surgical procedure; Orbital neoplasms.

\section{INTRODUCTION}

Angioleiomyomas are benign soft tissue tumors containing mature smooth muscle cells with a conspicuous vascular component. They usually develop in middle-aged women as small, firm, mobile nodules in the subcutaneous tissue or dermis of the lower extremity [1].

Since angioleiomyoma was firstly described by Stout, over 500 cases were reported [2]. However, orbital angioleiomyomas are extremely rare, and to date, only 35 cases have been reported based on pathology in the literature [3-8]. Among them, only 5 cases arose from orbital apex [3]. We herein report a case of angioleiomyoma located in the orbital apex which was successfully removed with simultaneous endoscopic and microscopic endonasal approaches.

\section{CASE REPORT}

\section{History and examinations}

A 56-year-old woman without history of any medical disease suffered from progressive eyeball pain and blurred vision

This is an Open Access article distributed under the terms of the Creative Commons Attribution Non-Commercial License (https://creativecommons.org/licenses/by-nc/4.0) which permits unrestricted non-commercial use, distribution, and reproduction in any medium, provided the original work is properly cited.

Copyright ( $\odot 2019$ The Korean Brain Tumor Society, The Korean Society for NeuroOncology, and The Korean Society for Pediatric Neuro-Oncology on her right side for 4 years. MRI demonstrated a small mass in the right orbital apex with significant optic nerve compression. T2-weighted MRI showed a slightly hyperintense nodular mass in the apex of right orbit. The mass was isointense in T1-weighted MRI, which was homogeneously enhanced in T1-weighted MRI with gadolinium (Fig. 1A, B). Based on the MR images, preoperative diagnosis included an orbital hemangioma or a schwannoma. On the coronal view, optic nerve was compressed by the mass and deviated to superomedial side of intraconal space (Fig. 1C). Neurological examination revealed prompt isocoric pupillary reflex with normal range of motion of extra ocular muscles. Humphrey test revealed upper half field defect on the right side with -20.01 of mean deviation and $31 \%$ of visual field index. (Fig. 1D).

\section{Operation and surgical findings}

As the visual field defect was progressively worsened, the patient underwent surgical resection. Under right unilateral endoscopic endonasal approach, middle turbinate was reflected medially. Uncinate process and bullae ethmoidale were resected first. Then, posterior ethmoidectomy was performed until the entire medial wall of the right orbit was exposed. After removal of lamina paprycea, periorbita was incised and the tumor was accessed through the space between medial rectus and inferior rectus muscles under navigation guidance. Tumor was found at the innermost of the orbital 

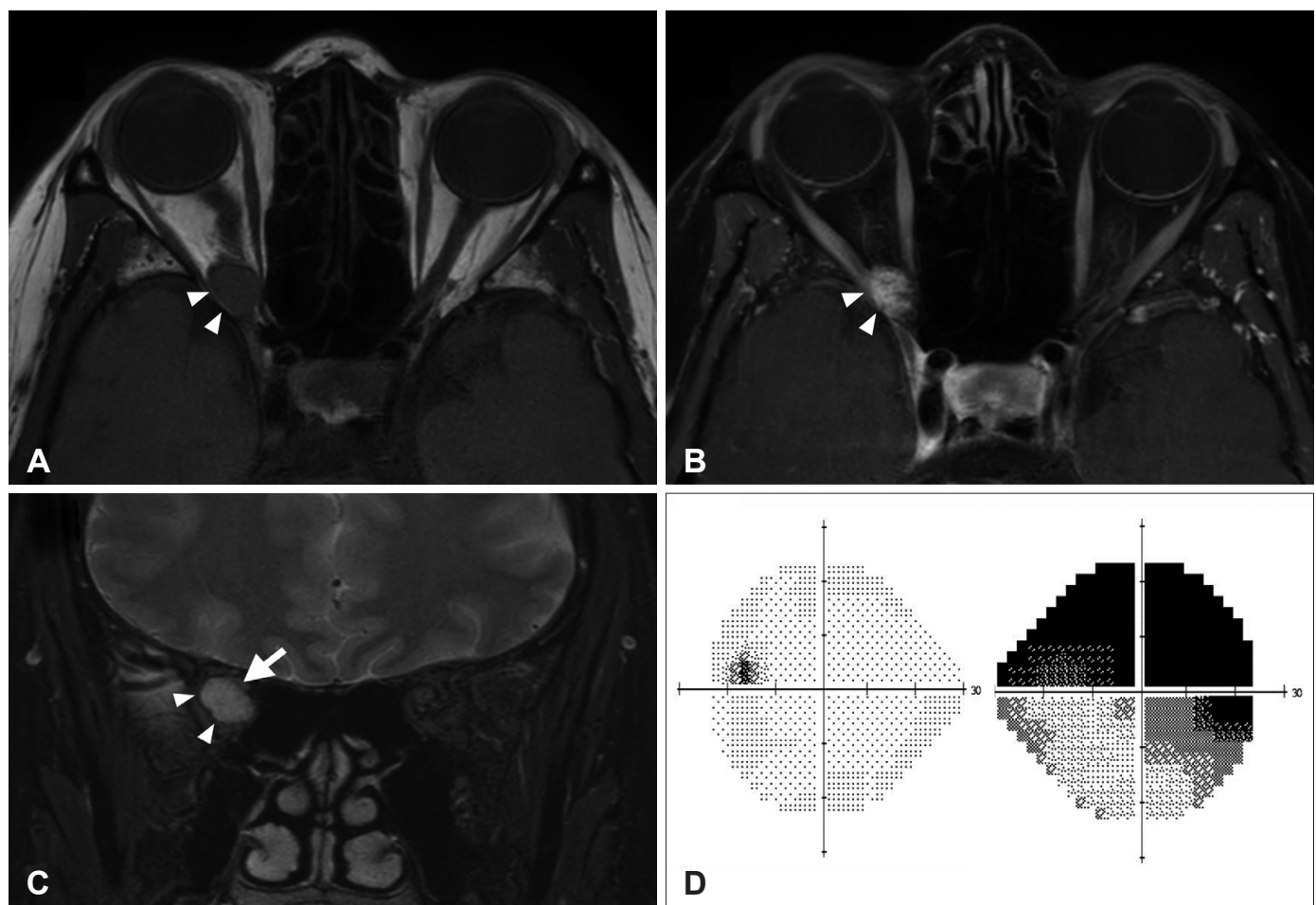

Fig. 1. Preoperative MRI and visual field test. A: T1-weighted image shows isointense $13 \mathrm{~mm}$-sized intraconal tumor (white arrow heads) at right orbital apex. B: T1-weighted contrast enhanced image shows homogeneous enhancement of the tumor (white arrow heads). C: T2weighted coronal image shows that the tumor (white arrow heads) is located at innermost of the orbital apex with superomedial compression of the right optic nerve (a white arrow). D: Visual field test reveals the patient could see only the bottom half of her right eye.

cone. The tumor was fibrous, hypervascular and very adhesive to adjacent structures. As the tumor was located at the very apex of the orbit, the space between medial and inferior rectus muscles was very narrow, which limited surgical maneuverability under endoscopic view. We inserted a nasal speculum and directly accessed the orbital apex under microscopic visualization. The tumor was dissected carefully from optic nerve, oculomotor nerve and surrounding extraocular muscles, and removed in en bloc. Orbital wall was reconstructed with a piece of vomer.

\section{Pathological findings}

Tumor was composed of numerous collapsed vascular channels having myxoid and varying thickness in wall and large amounts of spindle cells. The spindle cells showed strong immunoreactivity to smooth muscle actin (Fig. 2).

\section{Postoperative course}

Postoperative MRI confirmed a complete resection of the tumor (Fig. 3A, B, C). The patient showed right complete oculomotor nerve palsy immediately after surgery, which completely recovered 3 months after surgery. Six-month postoperative Humphrey test showed near complete recovery of visual filed on right side with -1.35 of mean deviation and
95\% of visual field index (Fig. 3D). On one-year follow-up, MRI showed no evidence of recurrence. Our institutional review board approved the waiver of informed consent.

\section{DISCUSSION}

Angioleiomyoma is a benign soft tissue tumor consist of smooth muscle and endothelium with abundant vascular channels intervening by stroma composed of loose smooth muscle bundles including variable amounts of collagen, but not elastin [9]. It is known that angioleiomyoma is originated from smooth muscle component in the vessel wall. It means, theoretically, angioleiomyoma may develop in any parts of the body. During the dissection, the solid tumor was very adhesive to surrounding structures, however, we could not identify the origin of the tumor as there was no attachment to any of external ocular muscles. Surrounding smooth muscle fibers are relative well-organized but the storma is distorted [10]. Histologically, angioleiomyoma is divided into three subtypes based on the relative proportions of its components: solid, venous, and cavernous. The solid subtype is composed of compact smooth muscle and multiple small vascular channels. Venous angioleiomyomas are made up of loosely organized thick muscular walls enclosing vascular spaces. Lastly, the 

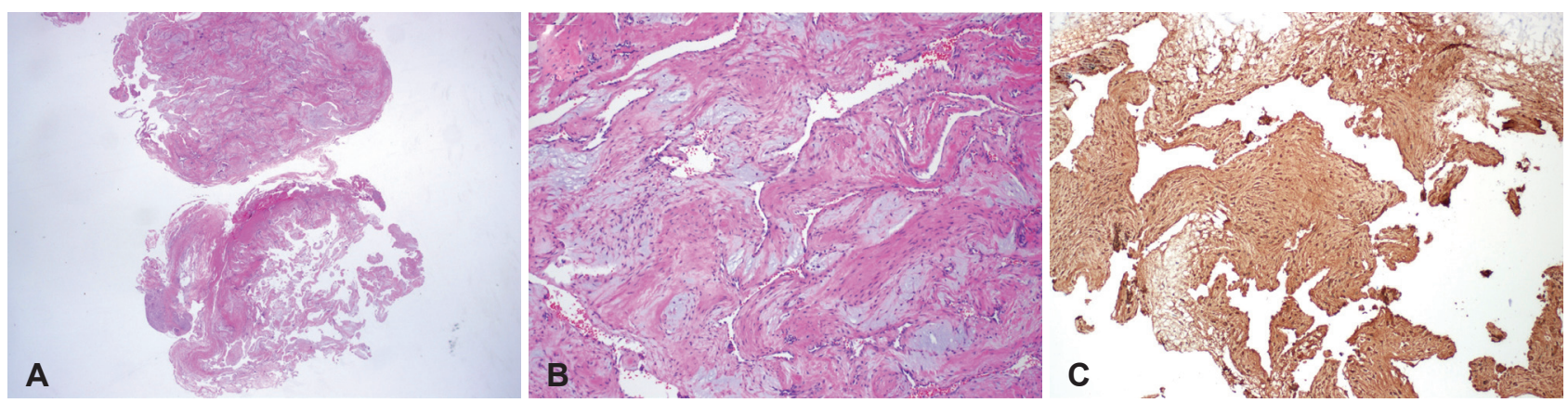

Fig. 2. Histopathological examination. A: In low power view $(H-E \times 12)$, a well demarcated soft tissue mass with many vascular channels are seen. B and C: In middle power view, smooth muscle cell proliferation (smooth muscle actin $\times 100$ ) with myxoid stroma surrounding vascular channel are noted $(\mathrm{H}-\mathrm{E} \times 100)$.
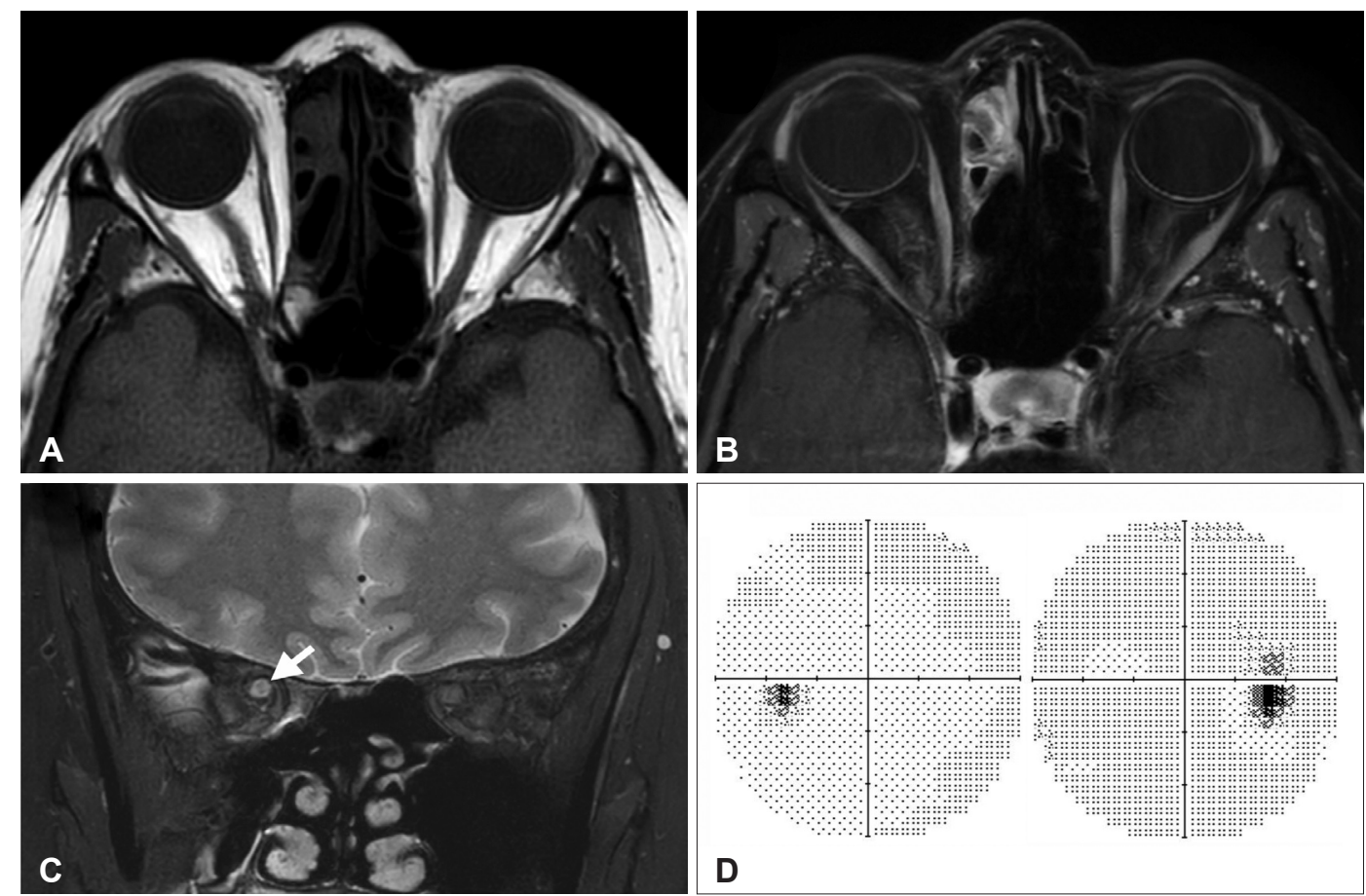

Fig. 3. Postoperative MRI and visual field test. A and B: T1-wighted image (A) and T1-weighted contrast enhanced image (B) shows that the tumor was totally resected. C: T2-weighted coronal image shows that the optic nerve is decompressed (a white arrow). D: Visual field test revealed that patient's right visual field defect was completely recovered one year after the surgery.

cavernous subtype is characterized by predominance of dilated vasculature and little smooth muscle [1]. Angioleiomyomas usually arise within the subcutaneous or deep dermal layers from the soft tissue of the lower extremity. These tumors show peak incidence rate between the fourth and six decades of life and has a slight female predominance. On the other hand, intraorbital angioleiomyomas are rare, and like intracranial angioleiomyoma, exhibit a male to female predominance of 4:1 [11]. Surgical excision is the treatment of choice for orbital angioleiomyoma and in case of incomplete excision, the patient should be followed closely since the tumor could re-grow even it is benign and could show newly developed symptoms [3]. Radiation therapy for remnant tumor is not recommended for it is radioresistant and even ra- diation may cause radiation-induced sarcoma [12].

Radiologically, theses masses are hyperdense on CT and homogeneously enhances with intravenous contrast administration [13]. The T1-weighted images show usually isointensity and the T2-weighted are hyperintense, also with uniform to so-called "flame-like" enhancement on postgadolinium images [14]. This enhancement pattern is due to its central arisen gadolinium moving out peripherally. The lesions should be distinguished with a similar imaging appearance including cavernous hemangiomas, meningiomas, schwannomas, and neurofibromas as well as other well-circumscribed masses [15].

Ladato described first of the orbital angioleiomyoma in 1896, and Nath and Shukla documented in the English-language 
medical literature for first time in 1963. Since then Arat et al. reviewed orbital angioleiomyomas of 26 well-documented cases and additional 9 cases were reported whereafter [3-8]. Among them five were displayed at orbital apex. Four tumors were removed through lateral orbitotomy and one was through frontotemporal approach. Three of them were excised incompletely and only two were completely resected [3]. Conventionally, various surgical approaches have been tried to treat orbital apex lesion: a medial approach by external ethmoidectomy, an inferomedial approach via a transantral transethmoidal route, a supraorbital transcranial approach [16]. This may imply that there is no single effective surgical route to approach orbital apex yet. Recently, endoscopic endonasal approach is rising as alternative gaining popularity for its minimally invasiveness and effectiveness to reach various skull base locations. In the present case, we chose firstly, endoscopic approach to reach the orbital apex and used transiently microscope to easily manipulate the firm, solid and small tumor with abundant vasculature.

In conclusion, although uncommon, angioleiomyomas should be considered in the differential diagnosis of well-circumscribed orbital mass since the treatment of choice is surgical resection which is very different from others like hemangioma, meningioma and schwannoma for its radioresistant character. Plus, there is no doubt that endoscopic transendonasal approach is excellent to take place conventional way to reach orbital apex, and rather be better if microscopic support is added in selected cases.

\section{Conflicts of Interest}

The authors have no potential conflicts of interest.

\section{REFERENCES}

1. Ramesh P, Annapureddy SR, Khan F, Sutaria PD. Angioleiomyoma: a clini- cal, pathological and radiological review. Int J Clin Pract 2004;58:587-91.

2. Conner TM, Waziri A, Kleinschmidt-Demasters BK. Angioleiomyomas of the dura: rare entities that lack KRIT1 mutations. Am J Surg Pathol 2012;36:526-33.

3. Arat YO, Font RL, Chaudhry IA, Boniuk M. Leiomyoma of the orbit and periocular region: a clinicopathologic study of four cases. Ophthalmic Plast Reconstr Surg 2005;21:16-22.

4. Jakobiec FA, Zakka FR, Papakostas TD, Fay A. Angiomyofibroma of the orbit: a hybrid of vascular leiomyoma and cavernous hemangioma. Ophthalmic Plast Reconstr Surg 2012;28:438-45.

5. Jakobiec FA, Zakka FR, Yoon MK. Complex orbital angiomyoma with features of a lymphangiohemangioma. Ophthalmic Plast Reconstr Surg 2013;29:e61-5.

6. Alam MS, Subramanian N, Koka K, Subramanian K. Orbital angioleiomyoma: a rare orbital neoplasm. Orbit 2016;35:113-6.

7. Nair AG, Jain V, Gopinathan I, Murthy A. Solid variant of orbital angioleiomyoma: an unusual tumor at an unusual site. Indian J Ophthalmol 2016;64:466-8.

8. Sato K, Ogawa Y, Kinoshita K, et al. [A case of an orbital angioleiomyoma]. No Shinkei Geka 2017;45:1087-92.

9. Gasco J, Franklin B, Rangel-Castilla L, Campbell GA, Eltorky M, Salinas P. Infratentorial angioleiomyoma: a new location for a rare neoplastic entity. J Neurosurg 2009;110:670-4.

10. Hachisuga T, Hashimoto H, Enjoji M. Angioleiomyoma. A clinicopathologic reappraisal of 562 cases. Cancer 1984;54:126-30.

11. Li D, Hao SY, Tang J, et al. Primary intracranial angioleiomyomas: diagnosis, treatment, and literature review. Brain Tumor Pathol 2014;31:101-7.

12. Jakobiec FA, Howard GM, Rosen M, Wolff M. Leiomyoma and leiomyosarcoma of the orbit. Am J Ophthalmol 1975;80:1028-42.

13. Delgado-Fernandez J, Penanes JR, Torres CV, Gordillo-Velez CH, Manzanares-Soler R, Sola RG. Infratentorial angioleiomyoma: case report and review of the literature. Rev Neurol 2016;62:68-74.

14. Sun L, Zhu Y, Wang H. Angioleiomyoma, a rare intracranial tumor: 3 case report and a literature review. World J Surg Oncol 2014;12:216.

15. Li CB, Xie MG, Ma JP, et al. Primary intracranial angioleiomyomas as rare, nonmalignant, and distinct neoplastic entities: a series of 8 cases and a literature review. World Neurosurg 2018;113:1-13.

16. Berhouma M, Jacquesson T, Abouaf L, Vighetto A, Jouanneau E. Endoscopic endonasal optic nerve and orbital apex decompression for nontraumatic optic neuropathy: surgical nuances and review of the literature. Neurosurg Focus 2014;37:E19. 